\title{
Globalisation and psychiatry
}

\author{
Brendan D. Kelly
}

\begin{abstract}
Globalisation means crossing borders. It is a complex, large-scale social phenomenon that presents to mental health services both challenges and opportunities. These relate to the increased cultural diversity of service users and service providers; the effects of migration on mental health; and the implementation of international protocols in relation to training, policy and education. In the aftermath of 11 September 2001 in the USA, the relationship between large-scale social change and mental health has also focused attention on the concepts of anomie and social capital. An explicit return to the principles of biopsychosocial psychiatry and a positive engagement with globalisation will advance the development of effective, evidence-based models of care appropriate to the changing needs of patients.
\end{abstract}

Globalisation means crossing borders. All of the social and economic forces driving globalisation relate to the opening or dismantling of borders: instant communication, easy travel, deregulation of commerce and widened access to information and technology. The internet is often hailed as a good example of globalisation, as it allows people in far-flung corners of the planet to communicate rapidly with each other regardless of their geographical location. Other examples include the establishment of supranational political bodies, enhanced cross-border cultural interaction and globalised approaches to environmental issues (Box 1).

From its inception, globalisation has attracted robust criticism, chiefly related to the social inequities it appears to accentuate. Critics point out that the internet, for example, remains the realm of a privileged minority as most of the world's population have never made a telephone call, let alone sent an e-mail. The free flow of capital into and out of unstable economies also presents problems, often compounded by the waves of migration that tend to

\section{Box 1 Key features of globalisation}

Instant communication (e.g. by the internet)

Fast, efficient means of travel

Deregulation of commerce

Widened access to technology

Supranational political bodies

Cross-border cultural interaction

Globalised approaches to environmental issues follow financial downturns (Stiglitz, 2002). Perhaps the greatest criticism of globalisation, however, relates to the management of cultural diversity, a phenomenon that presents very great challenges, as well as opportunities, in many societies around the world. These criticisms, along with the terrorist attacks of 11 September 2001 in the USA, have stimulated a worldwide re-evaluation of globalisation and a reconsideration of the strategies that societies and individuals use to manage global change.

In this article, I examine the effects of globalisation on the practice of psychiatry and suggest strategies for their optimal management in relation to mental health with a view to exploiting the opportunities it presents for the development of psychiatric services.

\section{Socio-economic effects and their impact on mental health}

There is considerable disagreement among economists about the likely long-term economic effects of globalisation. On the one hand, it is argued that the process of globalisation offers individuals more freedom to choose how they live, where they work and what they buy (Economist, 2001). Opening borders, deregulating trade and using government chiefly to maintain social justice should, it is argued, lead to a more integrated, more equitable and more sustainable global society. This view actively informs the current policies of international organisations such as the World Bank, the International Monetary Fund and the World Trade Organization.

Brendan D. Kelly is Stanley Research Fellow in Psychiatry in Dublin (Department of Adult Psychiatry, Hospitaller Order of St John of God, Cluain Mhuire Service, Newtownpark Avenue, Blackrock, Co. Dublin, Ireland. Tel.: +353 12833 766; fax: +353 1 2833 886; e-mail: brendankelly35@hotmail.com). His research interests include the epidemiology of psychosis and the relationship between mental illness and social factors. He was joint winner of the Gaskell medal and prize in 2003. 
Critics of globalisation argue the opposite case, maintaining that current globalisation policies serve to widen the gap between rich and poor (Stiglitz, 2002). Market deregulation favours the dominant, strong economies of the West and fails to offer developing countries an opportunity to strengthen their infrastructure sufficiently to compete in a global economy. Globalisation, by this logic, will lead to further poverty, inequality and social injustice.

The majority of commentators from both sides, however, are united on one point: that globalisation presents opportunities that could, at least in theory, be used for the greater good. The chief point of disagreement is the sequencing of change, with certain critics arguing that it is wrong to deregulate markets without first preparing an economy and a society for change. They point to evidence from the World Bank that shows little decrease in world poverty and a possible increase in inequality between countries in recent years (World Bank, 2001).

Socio-economic and other inequalities are significantly related to mental health. Psychiatric disorders are more common in people from lower socio-economic groups (Goldberg \& Morrison, 1963; Wiersma et al, 1983). This relationship is likely to be bi-directional, with health affecting socio-economic status and socio-economic status also affecting health (Lewis \& Araya, 2002). Thus, if globalisation truly increases poverty, it is likely to have a proportionately negative effect on mental health. This effect would be compounded by the decreasing ability of an increasingly poor country to provide adequate health care to its citizens. An effect on social capital would also be evident, with reduced community cohesiveness, resulting in weakened social support and increased psychosocial morbidity (Putnam, 2000).

It is likely that a disproportionate part of this burden would be borne by women, who, in addition to performing the majority of domestic and childcare tasks, may find themselves satisfying a growing need for relatively low-paid labour (Lewis \& Araya, 2002). In light of the particular importance of psychosocial stressors in relation to depression in women (Avotri \& Walters, 1999), such a change would be expected to increase the incidence of depression and anxiety among them.

This is the worst-case scenario: increased poverty, increased illness burden and decreased ability to provide mental health care. The socio-economic effects of globalisation, however, need not be entirely negative. Indeed, several important features of this process suggest that globalisation, if properly managed, can serve as a force for the promotion of economic growth and the enhancement of social capital in both developed and developing countries. Communication technology is a good example.
At present, advances in communication technology are not equitably distributed around the world. However, this technology is spreading rapidly from developed countries to developing ones and it has a strong enabling power when it arrives. The internet, for example, can be used to inform farming and fishing practice by providing information relating to prices, markets and weather forecasts (Economist, 2001). In countries such as Bangladesh, mobile telephone networks are proving far more efficient than traditional terrestrial telephones, as each person in a village might make only one or two calls per week and terrestrial telephone systems are either unavailable or administered by inefficient, bureaucratic government bodies. Advances in communications technology have much to offer developed nations too: even critics of globalisation use the internet extensively to organise protests and coordinate campaigns.

There is no compelling reason to believe that globalisation must necessarily increase the gap between rich and poor. Globalisation on this scale and at this speed is a new phenomenon. Our economic and social policies in response to it are probably responsible, at least in part, for any perceived negative effects. Just as Stiglitz (2002) argues for an urgent reconsideration of economic policies in response to globalisation, there is a similar need to re-evaluate social policy. There is a strong relationship between socio-economic change and mental health, and this relationship should form an important part of social, economic and health planning. This point is well illustrated by the significant challenges that increased migration currently presents to mental health services.

\section{Migration and mental illness}

Globalisation has led to a significant increase in migration. People are now moving further, faster and in greater numbers than ever before. Each year, 1.5 million people emigrate permanently and a further 1 million seek asylum abroad (Stalker, 1994). Migration is known to have significant effects on health, with migrants showing higher rates of both physical (Gleize et al, 2000) and mental illness (Gavin et al, 2001).

In the UK, Irish, Caribbean and Pakistani immigrants have significantly higher rates of suicidal thoughts and deliberate self-harm (Nazroo, 1997). Egyptian and Asian immigrants have increased rates of bulimia and anorexia nervosa (Bhugra \& Jones, 2001). Asylum-seekers present particular challenges to mental health services as they come from a wide variety of cultural backgrounds and have sharply diminished social 
Box 2 Mental health of asylum-seekers: particular challenges

In their home country

Human rights abuse

Torture

Displacement

Poor mental health care

In their new country

Diminished social support

Confinement in detention centres

Enforced dispersal

Ongoing discrimination

Adjustment disorder

Post-traumatic stress disorder

Depression

Increased rates of other illnesses

support. Many have experienced human rights abuse, torture or displacement in their homeland (Box 2). On arrival in a new country, they might face confinement in detention centres, enforced dispersal and ongoing discrimination (Silove et al, 2000). In Oslo, post-traumatic stress disorder affects $46.6 \%$ of all refugees (Lavik et al, 1996).

Schizophrenia is six times more common in African-Caribbeans living in the UK than in the native population (Harrison, 1990) and four times more common among migrants to The Netherlands (Selten et al, 1997). This is difficult to explain: incidence of schizophrenia is not increased in migrants' countries of origin (Hickling \& Rodgers-Johnson, 1995), nor do migrants have increased exposure to environmental risk factors such as obstetric complications (Hutchinson et al, 1997). It is notable, however, that the increase in risk of schizophrenia among migrants shows a powerful inverse relation with the size of the migrant group, a finding that, at the present state of biological psychiatry, lends itself more readily to psychosocial explanations than to biological ones (Boydell et al, 2001).

Globalisation, then, affects the pattern of occurrence of mental illness and, through migration, has had a significant effect on the epidemiology of schizophrenia. The increased diversity of mental health service users presents an urgent challenge to service providers in developed countries. People from different ethnic backgrounds often have different views about mental health and are accustomed to substantially different models of care. This can result in a damaging mismatch between the needs of patients and the services provided. In London, for example, the pathway to care for migrants is characterised by a high rate of involuntary admission and increased involvement of police, as opposed to general practitioners (Davies et al, 1996).
In response to these problems, it is necessary to address issues in psychiatric training, service provision and social policy. In the first instance, it is important to increase the emphasis placed on transcultural psychiatry in mental health curriculums. To assist with this task, the World Psychiatric Association is developing a core curriculum that places significant emphasis on transcultural issues (World Psychiatric Association, 2002). An enhanced appreciation of cultural factors as they affect mental health will serve both to deepen the understanding of cultural diversity and to enhance the quality and acceptability of the mental health care provided to all.

The development of ethnically segregated services, however, would tend to maintain racism and compound psychological stressors, and thus represents an inappropriate model for service development (Bhui et al, 2000). It is generally more helpful to increase knowledge of mental illness among migrants themselves and to provide appropriate training for mental health team workers to provide effective, needs-based interventions for specific migrant communities. There is also a strong need to reconsider the effects of social policies on the psychological well-being of migrants, as current policies of dispersement may serve to increase the psychological stresses and social disadvantages experienced by certain migrant groups.

\section{Globalisation and human rights in psychiatry}

Opponents of current models of globalisation often claim that it has negative effects on human rights, particularly in relation to financial well-being and economic stability. This is an issue of special concern in relation to people with mental illness particularly those with long-term illness who have reduced ability to advocate for themselves. In 1991, the rights of those with mental illnesses were 'globalised' in the United Nations' Principles for the Protection of Persons with Mental Illness (United Nations, 1991) (Box 3). These principles, however, do not have the status of a formal international treaty and there is no obligation on UN member states to use the principles to define a minimum standard of care (Harding, 2000).

In 2001 the World Health Organization renewed its emphasis on human rights and mental health by devoting World Health Day 2001 to global advocacy on mental health issues. There were compelling social, political and legislative reasons for this choice, many of which relate to the effects of globalisation. Migration, for example, presents particular challenges in terms of both health care 
Box 3 Key rights of people with mental illnesses and principles regarding their mental health care (United Nations, 1991)

- All people are entitled to receive the best mental health care available and to be treated with humanity and respect

- There shall be no discrimination on the grounds of mental illness. All people with mental illnesses have the same rights to medical and social care as other ill people

- All people with mental illnesses have the right to live, work and receive treatment in the community, as far as possible

- Mental health care shall be based on internationally accepted ethical standards, and not on political, religious or cultural factors

- The treatment plan shall be reviewed regularly with the patient

- Mental health skills and knowledge shall not be misused

- Medication shall meet the health needs of the patient and shall not be administered for the convenience of others or as a punishment

- In the case of voluntary patients, no treatment shall be administered without their informed consent, subject to some exceptions (e.g. patients with personal representatives empowered by law to provide consent). In the case of involuntary patients, every effort shall be made to inform the patient about treatment

- Physical restraint or involuntary seclusion shall be used only in accordance with official guidelines. Records shall be kept of all treatments

- Mental health facilities shall be appropriately structured and resourced

- An impartial review body shall, in consultation with mental health practitioners, review the cases of involuntary patients

and human rights. In the first instance, there is a basic human right to adequate health care and it is likely that migrants are being denied this in many countries around the world. Indeed, quality and availability of mental health care for both migrants and native populations present a real problem in many countries. In 2000 in Ethiopia, for example, a population of 55 million was served by 11 psychiatrists and one psychiatric hospital.

Alleged abuses of psychiatry around the world also provide cause for increasing concern. At the 2002 World Congress of Psychiatry in Yokohama, Japan, the World Psychiatric Association resolved to arrange a mission to China to investigate allegations of abuse of psychiatry there. It was agreed that the investigation of specific allegations would be set in the context of an examination of the overall quality of the psychiatric service in China. Issues relating to training, access to service and quality of care are important considerations in this context.

The evolution of a globalised approach to these issues, as demonstrated by the World Psychiatric Association, has many advantages. Most importantly, it provides a unified, authoritative voice with which to advocate for change. However, it is important to recognise that definitions of 'mental health' and 'psychiatry' can vary considerably between cultures. A solution that meets the needs of one country may not be appropriate for others. Furthermore, most legislatures have their own mental health laws, which often have substantially different approaches to issues such as involuntary admission and quality assurance. This is also a time of considerable legislative change in Europe, with many countries debating amendments to existing laws and at least one country (Ireland) introducing a completely new Mental Health Act.

The best way to ensure that human rights are respected on a global scale is to increase awareness and implementation of the United Nations' principles regarding people with mental illnesses (United Nations, 1991). These principles provide a framework that can usefully inform legislative change in individual countries. They should also form an important part of psychiatric education and can be used to help shape service developments and planning. The implementation of these principles is a challenging task, which is best accomplished when mental health professionals and policy makers work in partnership with advocacy groups and service-user representatives.

One of the central contributions that psychiatrists can make to this process is the continued provision of high-quality, evidence-based mental health care. Health care, however, is delivered in a specific social and political context, which is often largely determined by policy makers and politicians. Nevertheless, psychiatrists are well placed to educate colleagues, policy makers and the public about mental health and human rights. International 
psychiatric organisations such as the World Psychiatric Association have a particular role to play as powerful advocates for improved psychiatric care and for improved working conditions for mental health workers around the globe.

\section{Psychological effects of large-scale social change}

On 11 September 2001 the city of New York experienced the largest act of terrorism in the history of the USA, which took the lives of about 3000 people in New York alone ('Dead and missing', New York Times, 26 December 2001, B2). While certain commentators stated that these events heralded the 'end of globalisation', many others took the opposite view and concluded that there was now an even more urgent need for globalisation to proceed in a timely and equitable fashion (Economist, 2001).

In the months following the attacks, Galea et al (2001) studied the prevalence of post-traumatic stress disorder (PTSD) and depression in residents of Manhattan, the area most affected by the events. They interviewed over 1000 adults and found that $7.5 \%$ reported symptoms consistent with PTSD related to the attacks and $9.7 \%$ reported symptoms consistent with current depression. These prevalences were double those described in similar populations in the previous year. The authors then examined predictors of psychopathology and found that Hispanic ethnicity was associated with both PTSD and depression and that this association was independent of other covariates. PTSD and depression were also related to low social support. The authors emphasise that social ties have a positive and protective role in mental health.

Social ties, however, are rapidly decreasing in the USA, as evidenced by reduced participation in community organisations, local representation and national politics (Putnam, 2000). The events of 11 September were devastating not only because of their nature, magnitude and unpredictability, but also because they occurred in the context of a society with rapidly depleting social capital.

The combination of poor social ties and large, unpredictable events evokes the concept of 'anomie'. This term was famously used by Emile Durkheim, a French sociologist, to describe a state in which norms are confused, unclear or absent, and where there are large-scale social changes that the individual cannot understand, let alone control (Durkheim, 1947). Anomie is traditionally related to suicide, but the concept has also been suggested as one of a range of factors that might help to explain the increased incidence of schizophrenia in progressively smaller migrant groups (Boydell et al, 2001).
The concept of anomie has renewed importance in an era of globalisation. Changes in society are increasingly occurring on a global level and the magnitude of such change is greater than ever before. International political bodies are introducing directives and legislation over which many individuals feel they have little or no control. The threat of international terrorism is greater than ever and many individuals feel that they cannot effectively defend themselves or their families. Increasingly, the world of the individual is shaped by global events that appear to lie beyond the individual's control.

Rebuilding social capital is a key stage in reducing feelings of anomie. This is important for society in general, but has added urgency in relation to mental illness. The reduction of the stigma of mental illness is a particularly important step and is best accomplished through a multi-disciplinary approach over a sustained period. Community treatment programmes and social skills courses have critical roles to play in reducing stigma, increasing community reintegration and rebuilding social capital. This process would be advanced by a strong return to the principles of biopsychosocial psychiatry, which takes a systematic, multi-dimensional approach to treating mental illness (Gabbard \& Kay, 2001).

\section{Conclusion}

Globalisation is a complex, large-scale social phenomenon which is intrinsically neither good nor bad. The effects of globalisation depend largely on our engagement with it. There is a strong need to reevaluate our economic and social policies in response to globalisation, particularly with regard to the effects of socio-economic change on mental health. There are overwhelming humanitarian reasons why the relationship between socioeconomic change and mental illness should form an important part of social, economic and health planning. There are also financial reasons: schizophrenia, for example, already costs the US economy some $\$ 40$ billion per year - three times as much as the entire US space programme (Torrey, 2001).

The likely effects of globalisation on clinical practice in psychiatry are summarised in Box 4 . Globalisation presents significant opportunities for the development of psychiatric services. Whether or not we take advantage of these opportunities depends largely on our responses to phenomena such as increased migration and the increasingly diverse needs of mental health service users. The World Psychiatric Association's introduction of a 'core curriculum' for psychiatric training should assist in placing new emphasis on transcultural 
Box 4 Summary of the likely effects of globalisation on clinical practice

Increased ethnic and cultural diversity of service users, with a wider range of attitudes and beliefs in relation to mental illness

Increased ethnic and cultural diversity of service providers, with a wider range of approaches and beliefs in relation to mental health care

In developed countries, increased rates of inward migration and increased rates of migration-associated mental illnesses

In rapidly developing countries, increased rates of mental illnesses associated with social change, economic change and life events

In all countries, increased access to a range of health care information through global media such as the internet

Increased emphasis on the implementation of international protocols in psychiatric training, mental health policy and the protection of human rights

Increased examination of the concept of social capital and its influence on the mental health of populations

issues in psychiatry. In terms of service provision, there is a strong need to train mental health team workers to provide effective, needs-based interventions for specific migrant communities. Social policies in relation to migration (e.g. enforced dispersion) also require reconsideration as they can increase the psychological stresses and social disadvantages experienced by migrant groups.

The best way to protect the rights of mentally ill people on a global scale is to work with advocay groups and service-user representatives to implement the United Nations' principles for their protection (United Nations, 1991). Psychiatrists can make a major contribution to this process by providing high-quality, evidence-based mental health care. International psychiatric organisations have a crucial role as powerful advocates for improved psychiatric care and working conditions for all mental health workers.

Finally, research performed in the aftermath of 11 September 2001 in the USA emphasises the importance of social ties and social capital in protecting mental health. Emile Durkheim's concept of anomie has new relevance in light of the dramatic decrease in social capital recently described in the USA and elsewhere. Rebuilding social capital is important for society in general, but is particularly urgent in relation to mental illness. Integrated treatment programmes have a critical role to play in reducing the stigma of mental illness, enhancing community reintegration and increasing social capital.

Rebuilding social capital is a challenging task that depends on a careful interplay of local, national and international strategies. Globalisation can contribute positively to this process, provided social and economic policies in response to globalisation are planned with care. As mental health professionals, we are well positioned to advocate that such planning takes adequate account of the needs of people with psychiatric illness and facilitates the delivery of mental health care that is effective, acceptable, evidence-based and appropriate to the needs of patients.

\section{References}

Avotri, J. Y. \& Walters, V. (1999) 'You just look at our work and see if you have any freedom on earth': Ghanaian women's accounts of their work and their health. Social Science and Medicine, 48, 1123-1133.

Bhugra, D. \& Jones, P. (2001) Migration and mental illness. Advances in Psychiatric Treatment, 7, 216-222.

Bhui, K., Bhugra, D. \& McKenzie, K. (2000) Specialist Services for Minority Ethnic Groups? (Maudsley Discussion Paper no. 8). London: Institute of Psychiatry.

Boydell, J., van Os, J., McKenzie, K., et al (2001) Incidence of schizophrenia in ethnic minorities in London: ecological study into interactions with environment. BMJ, 323, 1336-1338.

Davies, S., Thornicroft, G., Leese, M., et al (1996) Ethnic differences in risk of compulsory psychiatric admission among representative cases of psychosis in London. BMJ, 312, 533-537.

Durkheim, E. (1947) The Division of Labour in Society (trans. George Simpson). New York: Free Press.

Economist (2001) Globalisation. London: Economist/Profile.

Gabbard, G. O. \& Kay, J. (2001) The fate of integrated treatment: whatever happened to the biopsychosocial psychiatrist? American Journal of Psychiatry, 158, 19561963.

Galea, S., Ahern, J., Resnick, H., et al (2001) Psychological sequelae of the September 11th terrorist attacks in New York City. New England Journal of Medicine, 346, 982-987.

Gavin, B. E., Kelly, B. D., Lane, A., et al (2001) The mental health of migrants. Irish Medical Journal, 94, 229-230.

Gleize, L., Laudon, F., Sun, L. Y., et al (2000) Cancer registry of French Polynesia: results for the 1900-1995 period among native and immigrant population. European Journal of Epidemiology, 16, 661-667.

Goldberg, E. M. \& Morrison, S. L. (1963) Schizophrenia and social class. British Journal of Psychiatry, 109, 785-802.

Harding, T. W. (2000) Human rights law in the field of mental health: a critical review. Acta Psychiatrica Scandinavica Supplementum, 399, 24-30.

Harrison, G. (1990) Searching for the causes of schizophrenia: the role of migrant studies. Schizophrenia Bulletin, 16, 663671.

Hickling, F. W. \& Rodgers-Johnson, P. (1995) The incidence of first contact schizophrenia in Jamaica. British Journal of Psychiatry, 167, 193-196.

Hutchinson, G., Takei, N., Bhugra, D., et al (1997) Increased rate of psychosis among African-Caribbeans in Britain is not due to an excess of pregnancy and birth complications. British Journal of Psychiatry, 171, 145-147.

Lavik, N. J., Hauff, E., Skrondal, A., et al (1996) Mental disorder among refugees and the impact of persecution and exile: some findings from an outpatient population. British Journal of Psychiatry, 169, 726-732.

Lewis, G. \& Araya, R. (2002) Globalization and mental health. In Psychiatry in Society (eds N. Sartorius, W. Gaebel, J. J. Lopez-Ibor, et al), pp. 57-78. Chichester: Wiley. 
Nazroo, J. (1997) Ethnicity and Mental Health. London: PSI. Putnam, R. D. (2000) Bowling Alone: The Collapse and Revival of American Community. New York: Touchstone.

Selten, J. P., Slaets, J. P. \& Kahn, R. S. (1997) Schizophrenia in Surinamese and Dutch Antillean immigrants to The Netherlands: evidence of an increased incidence. Psychological Medicine, 27, 807-811.

Silove, D., Steel, Z. \& Watters, C. (2000) Policies of deterrence and the mental health of asylum seekers. JAMA, 284, 604611.

Stalker, P. (1994) The Work of Strangers. London: International Labour Organization.

Stiglitz, J. (2002) Globalization and its Discontents. London: Penguin.

Torrey, E. F. (2001) Surviving Schizophrenia. New York: HarperCollins.

United Nations (1991) Principles for the Protection of Persons with Mental Illnesses and the Improvement of Mental Health Care. New York: United Nations.

Wiersma, D., Giel, R., De Jong, A., et al (1983) Social class and schizophrenia in a Dutch cohort. Psychological Medicine, 13, 141-150.

World Bank (2001) World Development Report 2000/2001. New York: Oxford University Press.

World Psychiatric Association (2002) Draft Core Curriculum. http://www.wpanet.org/sectorial/docs/draft $\% 20$ core $\%$ curriculum.zip)

\section{Multiple choice questions}

1 In relation to migration:

a 5 million people emigrate permanently each month

b 1 million people seek asylum abroad each year

c migration has reduced in recent years

d 1.5 million people emigrate permanently each year

e migration is not a key feature of globalisation.

2 In relation to migration and health:

a migration is related to risk of mental illness

b migration improves physical health

c asylum-seekers rarely present with post-traumatic stress disorder

d migrants have higher rates of involuntary admission than native populations

e schizophrenia is less common in migrants than in native populations.
3 The United Nations' Principles for the Protection of Persons with Mental Illness:

a were introduced by the World Health Organization

b date from the 20th century

c have the status of a formal international treaty

d provide a framework for legislative change in individual countries

e could usefully inform programmes of psychiatric education.

4 Following the events of 11 September 2001 in the USA:

a the prevalence of post-traumatic stress disorder in Manhattan increased

b the prevalence of depression in Manhattan increased

c psychopathology was unrelated to Hispanic ethnicity

d psychopathology was related to pre-existing social ties

e commentators began to re-evaluate policies related to globalisation.

5 The concept of anomie:

a was introduced by Putnam

$\mathrm{b}$ is unrelated to suicide

c relates to the belief that aliens are taking over the earth

$\mathrm{d}$ is related to psychosocial distress in times of change

e has added significance in the context of globalisation.

\begin{tabular}{|c|c|c|c|c|}
\hline 1 & 2 & 3 & & 4 \\
\hline F & a $\mathrm{T}$ & & F & a $\mathrm{T}$ \\
\hline $\mathrm{T}$ & $b \quad F$ & & $\mathrm{~T}$ & b $\mathrm{T}$ \\
\hline $\mathrm{F}$ & C F & & $\mathrm{F}$ & c F \\
\hline $\mathrm{T}$ & $\mathrm{d} T$ & & $\mathrm{~T}$ & $\mathrm{~d} T$ \\
\hline $\mathrm{F}$ & e F & & $\mathrm{T}$ & e $\mathrm{T}$ \\
\hline
\end{tabular}

\section{INVITED COMMENTARY ON Globalisation and psychiatry}

Dr Kelly's paper (Kelly, 2003, this issue) is a timely review of the effect of globalisation on mental health and its impact on psychiatric services and of the role that psychiatrists and their professional organisations can play in responding to this phenomenon.
Globalisation, defined by Kelly as 'crossing borders', is, as he points out, not a new phenomenon. Indeed, peoples have moved around the world, probably since time immemorial, and one need look no further than the Bible for confirmation that many of the reasons for these movements were 